\title{
Simulation of stratospheric water vapor and trends using three reanalyses
}

\author{
M. R. Schoeberl ${ }^{1}$, A. E. Dessler ${ }^{2}$, and T. Wang ${ }^{2}$ \\ ${ }^{1}$ Science and Technology Corporation, Lanham, MD, USA \\ ${ }^{2}$ Texas A\&M University, College Station, TX, USA \\ Correspondence to: M. R. Schoeberl (mark.schoeberl@mac.com) \\ Received: 26 February 2012 - Published in Atmos. Chem. Phys. Discuss.: 29 March 2012 \\ Revised: 25 June 2012 - Accepted: 29 June 2012 - Published: 24 July 2012
}

\begin{abstract}
The domain-filling, forward trajectory calculation model developed by Schoeberl and Dessler (2011) is extended to the 1979-2010 period. We compare results from NASA's MERRA, NCEP's CFSR, and ECMWF's ERAi reanalyses with HALOE, MLS, and balloon observations. The CFSR based simulation produces a wetter stratosphere than MERRA, and ERAi produces a drier stratosphere than MERRA. We find that ERAi $100 \mathrm{hPa}$ temperatures are cold biased compared to Singapore sondes and MERRA, which explains the ERAi result, and the CFSR grid does not resolve the cold point tropopause, which explains its relatively higher water vapor concentration. The pattern of dehydration locations is also different among the three reanalyses. ERAi dehydration pattern stretches across the Pacific while CFSR and MERRA concentrate dehydration activity in the West Pacific. CSFR and ERAi also show less dehydration activity in the West Pacific Southern Hemisphere than MERRA. The trajectory models' lower northern high latitude stratosphere tends to be dry because too little methane-derived water descends from the middle stratosphere. Using the MLS tropical tape recorder signal, we find that MERRA vertical ascent is $15 \%$ too weak while ERAi is $30 \%$ too strong. The trajectory model reproduces the observed reduction in the amplitude of the $100-\mathrm{hPa}$ annual cycle in zonal mean water vapor as it propagates to middle latitudes. Finally, consistent with the observations, the models show less than 0.2 ppm decade $^{-1}$ trend in water vapor both at mid-latitudes and in the tropics.
\end{abstract}

\section{Introduction}

The mechanisms responsible for stratospheric dehydration have been studied for more than $60 \mathrm{yr}$ - since the publication of Brewer's seminal paper (Brewer, 1949). Aside from its possible effect on stratospheric ozone loss processes (KirkDavidoff et al., 1999; Vogel et al., 2011), the concentration of stratospheric water vapor may alter the stratospheric climate (Forster and Shine, 1999) and the surface radiative forcing (Solomon et al., 2010). To first order, dehydration of air occurs as air, rising toward the stratosphere, cools, water vapor saturates, ice forms and then falls out. Dehydration thus primarily depends on the air parcel temperature history, and simulations of the stratospheric water vapor concentration ultimately depend on accurate analyses of temperatures and air parcel movement (e.g. Mote et al., 1996; Fueglistaler et al., 2005, 2009; Liu et al., 2010).

General circulation models have a difficult time reproducing the observed concentration of water vapor in the tropical upper troposphere and lower stratosphere (UTLS) (Gettleman et al., 2010). These difficulties arise from temperature biases, the representation of sub-grid scale phenomena such as convective moistening (Zipser et al., 2006; Schiller et al., 2009; Corti et al., 2008; Tzella and LeGras, 2011) and gravity wave cooling (Jensen and Pfister, 2004). In Schoeberl and Dessler (2011) (hereafter SD2011), we used a Lagrangian forward domain-filling model to simulate water vapor in the stratosphere. In forward domain filling, we regularly release parcels in the upper troposphere so that hundreds of thousands of parcels eventually fill the stratosphere and provide a statistically robust population for analysis. This approach provides a continuous picture of the time evolution 
of stratospheric constituents and allows us to investigate issues that may be difficult to address with traditional backtrajectory approaches or with Eulerian models. For example, in the case of back trajectory or reverse domain fill trajectory calculations, many separate long backward runs would be required to achieve the same statistical equivalence as a single forward trajectory run. On the other hand, back trajectory calculations are preferred for determining air parcel origins to elucidate observations. Both forward and backward trajectory calculations also retain the history of the parcel, which is difficult to determine in Eulerian models. Furthermore, the standard advection schemes used in Eulerian models excessively diffuse the strong water vapor gradient at the tropopause (e.g. Prather et al., 2008).

This paper extends the results of SD2011 to longer periods as well as making use of the recently completed long term reanalyses by NASA, NOAA and ECMWF to produce integrations extending from 1979 to 2010 . Each of these models has different biases that impact water vapor. We also compare our simulations to each other and to observations from balloons and satellites.

\section{Model and observations}

\subsection{Reanalysis data sets and model set up}

The results shown here are for diabatic trajectory calculations as described in detail in SD2011. SD2011 used both diabatic and kinematic methods and found that the diabatic trajectories produce better results compared with observations so we restrict ourselves to diabatic calculations. The advantage of diabatic trajectories over kinematic trajectories was first noted by Danielson (1961). Subsequently, Schoeberl et al. (2003), Liu et al. (2011), Ploeger et al. (2010, 2011), and others confirmed that even today kinematic trajectories driven by modern assimilation models produce an excessively dispersive vertical velocity field. In the Modern Era Retrospective-Analysis for Research and Applications (MERRA) (Bosilovich et al., 2008; Rienecker et al., 2011), used in SD2011, the vertical velocities are time averaged to suppress the noise, but even after this averaging the residual enhanced dispersion can affect the water vapor (SD2011). Wohtlmann and Rex (2008) suggest use of the thermodynamic equation rather than the continuity equation to produce quieter stratospheric vertical velocities, but this is formally equivalent to diabatic trajectories.

Forward domain-filling works as follows: For each day, we initialize a grid of parcels at $360 \mathrm{~K}$ from $\pm 40^{\circ}$ latitude. The injection level is chosen to be above the zero diabatic heating level. The tropical parcels move upward into the stratosphere, filling the stratospheric domain. Parcels move downward at extra tropical latitudes and those moving below $250 \mathrm{hPa}$ are removed - we assume they have re-entered the troposphere. Parcels are initiated with 50 ppmv water va- por and we dehydrate parcels to saturation when the relative humidity crosses a predetermined threshold, e.g. $100 \%$. We use the temperature - water vapor saturation relationship described in Murphy and Koop (2005) to determine if parcels have reached saturation. As with most trajectory models of this type we assume that the excess water vapor is instantly removed. (We have performed experiments with slower removal, as might occur with ice crystal formation and gravitational settling, and found that this process has no noticeable impact on our results.) In addition to water vapor, we carry methane $\left(\mathrm{CH}_{4}\right)$ concentration for each parcel. Methane is oxidized and the resulting water is added to the parcel, as described in SD2011. Tropospheric methane initial values are increased from $1.54 \mathrm{ppmv}$ in 1979 to $1.8 \mathrm{ppmv}$ in 2010 , and the oxidation rate of methane comes from a twodimensional stratospheric chemistry model (Fleming et al., 2007). We save the location of the final dehydration point (FDP) for each parcel. The FDP has also been referred to in the literature as the Lagrangian dry point (e.g., Liu et al., 2010).

In addition to MERRA assimilated data, we now include the NOAA's Climate Forecast System Reanalysis (CFSR, Saha et al., 2010) and ECMWF's ERA Interim reanalysis (ERAi, Dee et al., 2011). The diabatic heating rates include the radiative effects of clouds. These three reanalyses are described and compared in more detail at http://reanalyses.org/ atmosphere/comparison-table. For each run we use the convective moistening and gravity wave schemes described in SD2011. Our ERAi data set is archived every six hours while the MERRA and CFSR are archived daily. We have recently used a six-hour MERRA data set and our preliminary analysis shows that MERRA six-hour data produces a stratosphere as dry as ERAi because the higher time resolution better resolves lower temperatures along the parcel path leading to more dehydration. The high time resolution MERRA data, for example, shows a diurnal cycle in temperature that is removed by daily averaging. This suggests that the higher time resolution is now explicitly including some of the temperature variability implicitly added through our gravity wave scheme (SD2011).

\subsection{Observations}

Our trajectory model water vapor calculations are compared to both satellite and balloon observations. The longest high quality balloon observations are the Boulder data, which extends back 30 years (Rosenlof et al., 2008; Hurst et al., 2011). We also use satellite data, beginning with the 1993-2005 UARS Halogen Occultation Experiment (HALOE) measurements (Evans et al., 1998) and continue with the 2005 to 2010 Aura Microwave Limb Sounder (MLS) measurements (Read et al., 2007). We adjust the HALOE time series so the 2005 average water vapor at each latitude and pressure level equals the 2005 average MLS data. This offset (MLS-HALOE) is $\sim 0.6 \mathrm{ppmv}$ at $100 \mathrm{hPa}$ the equator. 


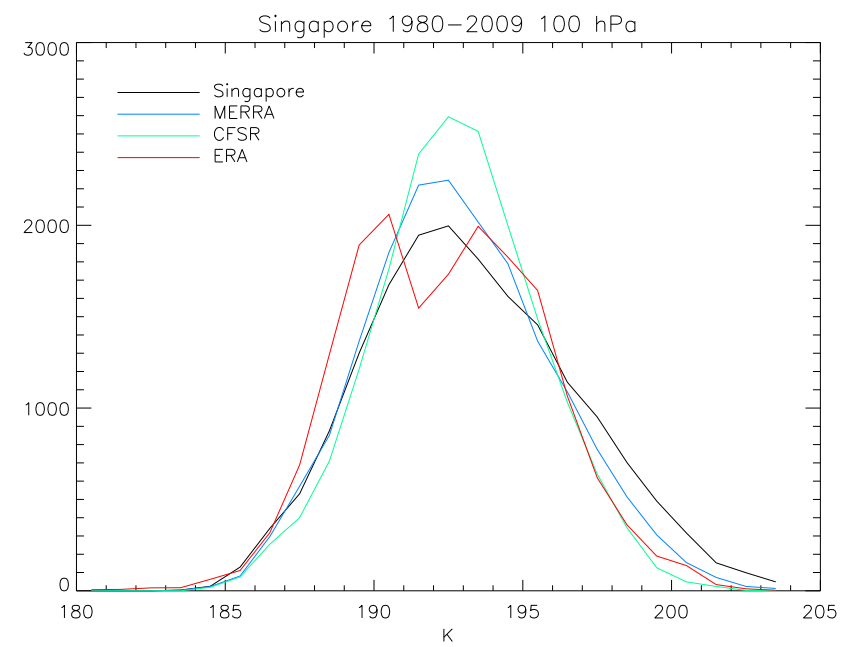

Fig. 1a. PDF of $100 \mathrm{hPa}$ winter (DJF) temperatures at Singapore and for the three reanalyses (with units of number of observations per K).

\subsection{Reanalysis tropical temperature differences}

As noted above, the most important factor in controlling stratospheric water vapor in the tropical UTLS is temperature. Figure $1 \mathrm{a}-\mathrm{b}$ compare the $100 \mathrm{hPa}$ temperatures at Singapore $\left(1^{\circ} 14^{\prime} \mathrm{N}, 103^{\circ} 55^{\prime} \mathrm{E}\right)$ in the Tropical West Pacific (TWP) with the three reanalyses. We chose Singapore because it has the longest record of observations in the TWP, and although 100-hPa level is often just below the cold point, $100 \mathrm{hPa}$ is a standard level for temperature and water vapor data sets as well as for reanalyses. Later, our dehydration maps will show that Singapore lies within the tropical dehydration zone. For Fig. 1, the reanalyses are interpolated to the latitude and longitude and times of the Singapore measurements. The Aura Microwave Limb Sounder (MLS) winter water vapor measurements at $100-\mathrm{hPa}$ interpolated to the location of Singapore is $\sim 3$ ppmv. In this region, $\mathrm{CH}_{4}$ oxidation does not contribute to the water vapor concentration so we may assume that water vapor is totally controlled by dehydration/hydration processes. Figure 1a shows the 19792010 probability distribution function (PDF) of the Singapore sonde temperatures with the three reanalyses. MERRA shows the best agreement although the mean of both CFSR and MERRA are quite close. ERAi shows a weak bimodal distribution with the larger peak colder than the observations. The fluctuations in the Singapore temperatures have $\sim 0.7$ correlation with all the reanalyses. CFSR, MERRA and ERAi are also compared at http://gmao.gsfc.nasa.gov/ ref/merra/atlas/atlas.php and it is evident that ERAi is about $\sim 1 \mathrm{~K}$ colder than MERRA daily or CFSR daily for the boreal winter.

In Fig. 1b we plot the mean temperature of the three reanalyses and Singapore sondes and the saturation water vapor mixing ratio. Also plotted are the mean temperatures mi-

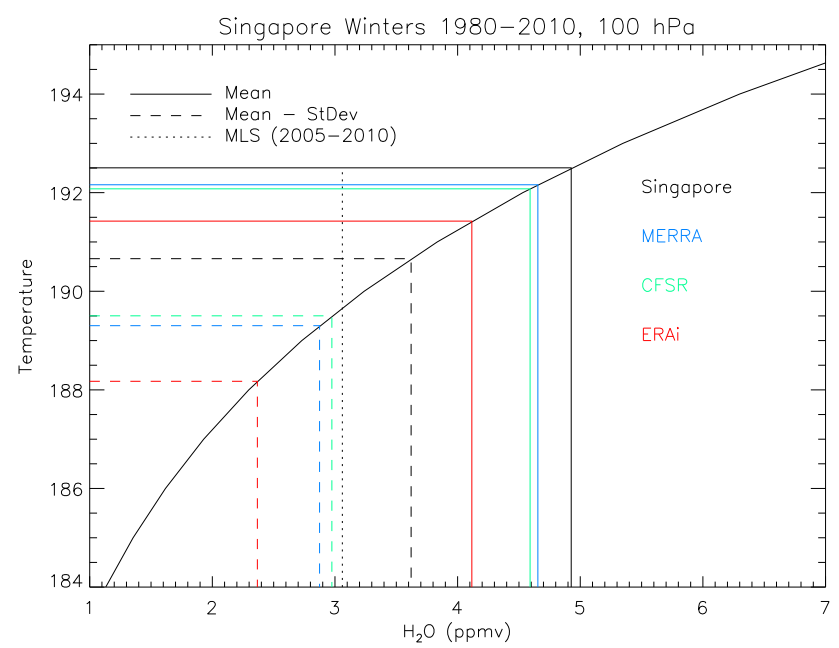

Fig. 1b. Winter temperatures and saturation water vapor concentration using Murphy and Koop (2005) for observations from Singapore and the three reanalyses at Singapore. Solid lines, mean temperatures from 1979-2010; dashed lines, one standard deviation below the mean. MLS (2005-2010) is zonal average of $100 \mathrm{hPa}$ observations for the months of DJF.

nus one standard deviation and the resultant water vapor mixing ratios compared to MLS. The figure shows how sensitive water vapor saturation mixing ratio is to the temperatures, $\sim 0.5 \mathrm{ppmv} \mathrm{deg}^{-1}$ at these pressures. Thus even a small bias in reanalysis temperatures can produce a significant shift in water vapor concentration (e.g. Randel et al., 2004).

\subsection{Model parameters}

As discussed in SD2011 we have three free parameters that we can adjust to control water vapor. These parameters are: (1) supersaturation, which is frequently observed to be $>100 \%$ near the tropical tropopause (Jensen et al., 2005; Kramer et al., 2009) - increasing the supersaturation threshold will increase the water vapor concentration; (2) the magnitude of high frequency gravity wave temperature fluctuations (Jensen and Pfister, 2004) - gravity waves reduce the water vapor by increasing the probability of parcels encountering colder temperatures; (3) the convective overshooting and ice injection - this will increase the water vapor concentration on the average (e.g. Wright et al., 2011). To parameterize convective ice injection we use the scheme developed by Dessler et al. (2007).

In SD2011 we found that increasing the supersaturation threshold to $104 \%$ increases stratospheric water vapor by about $0.1-0.25$ ppmv. Likewise the gravity wave parameterization scheme reduces water vapor concentration by an equivalent amount. Convective lofting of ice (as implemented in SD2011) increases the overall water vapor concentration by about $0.5 \mathrm{ppmv}$. Although our parameterization schemes for gravity waves, supersaturation and convective 

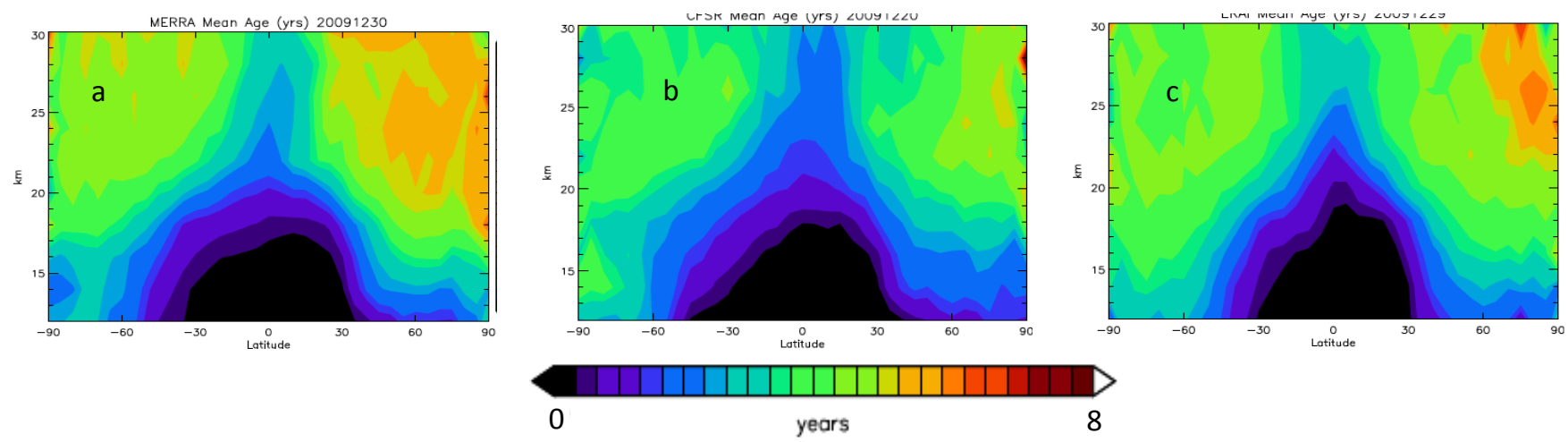

Fig. 2. Mean ages (years) for MERRA (a), CFSR (b), ERAi (c) computed in December 2009 after 30 yr integration.

lofting are loosely based upon observations, there are insufficient constraints to further isolate the roles of the individual schemes. In other words, we can also simulate the observed stratospheric water vapor by increasing the supersaturation from $104 \%$ to $120 \%$ while, at the same time, increasing the gravity wave amplitude by a factor of 2 . The two changes cancel each other yielding the same result and yet both changes are within the uncertainty of existing observations.

In addition to the uncertainty in the parameterization schemes, the analyses differ in their absolute temperature values near the tropopause, which can have a significant impact (e.g., Fig. 1b). For example, using the CFSR simulations produce a stratosphere that is $\sim 0.5 \mathrm{ppmv}$ wetter than MERRA. The main reason is that the vertical resolution of the temperature field in the TTL is coarser in CFSR (levels are about $\sim 2 \mathrm{~km}$ apart between 16 and $21 \mathrm{~km}$ ) than in MERRA ( $\sim 1-\mathrm{km}$ resolution). Linearly interpolating the CFSR temperatures across the tropopause produces a statistically warmer cold point compared to MERRA even though MERRA and CFSR 100-hPa temperatures are nearly the same.

\section{Results}

Before we address the long-term integrations and trends in Sect. 3.2, we first revisit some of the basic results from the SD2011 model. This first section can be viewed as an expansion of SD2011 to show the differences between CFSR and ERAi and MERRA reanalyses.

\subsection{Analysis comparisons}

\subsubsection{Mean age}

In Fig. 2 we show the mean age-of-air from trajectory calculations using the three analyses schemes, CFSR, MERRA and ERAi (hereafter we refer to the trajectory integrations using the name of the analysis). The MERRA and ERAi results show a well-defined narrow tropical pipe region (Plumb, 2002) compared to the CFSR. At high latitudes, MERRA and ERAi air is older than CFSR suggesting better tropical containment of air by the former.

\subsubsection{Dehydration patterns}

In Fig. 3, we show the final dehydration point (FDP) locations from the three reanalyses. To create this figure we generate a normalized PDF of dehydration points using a $9^{\circ}$ longitude by $2^{\circ}$ latitude grids. We consider only dehydration events for which the trajectory experienced no further dehydration events for at least a year to make sure that they are FDPs. The dehydration patterns are similar, including the large zone of dehydration over South America, although MERRA shows higher concentration of FDPs in the Southern Hemisphere compared to CFSR and ERAi. This difference arises from MERRA's enhanced convection over the southern part of the TWP, which is believed to be due to a problem with assimilation of the ATOVS (Advanced TIROS Operational Vertical Sounder) radiances (S. Pawson, private communication, 2011). The enhanced convection produces a colder tropopause and more frequent FDPs. MERRA also shows lower numbers of FDPs over Southeast Asia relative to the other reanalyses. CFSR and ERAi show similar patterns of dehydration except that ERAi stretches the dehydration zone across the Pacific along the ITCZ. Both ERAi and CFSR also show more dehydration occurring over SE Asia than MERRA.

The appearance of FDPs over Antarctica is due to the very cold temperatures within the Antarctic vortex during the Southern Hemisphere winter. Air that enters in the tropics is further dehydrated over Antarctica, which contributes to the overall drier air in Southern Hemisphere compared to the Northern Hemisphere (SD2011).

Figure 4 shows the mid-winter MLS V3.3 water vapor and computed using the three reanalyses. Each plot also shows the zonal mean temperature from each reanalysis. The MLS averaging kernels are sharp, providing a vertical resolution of about $\sim 3 \mathrm{~km}$ at the altitudes shown (see Read et al. (2007) 

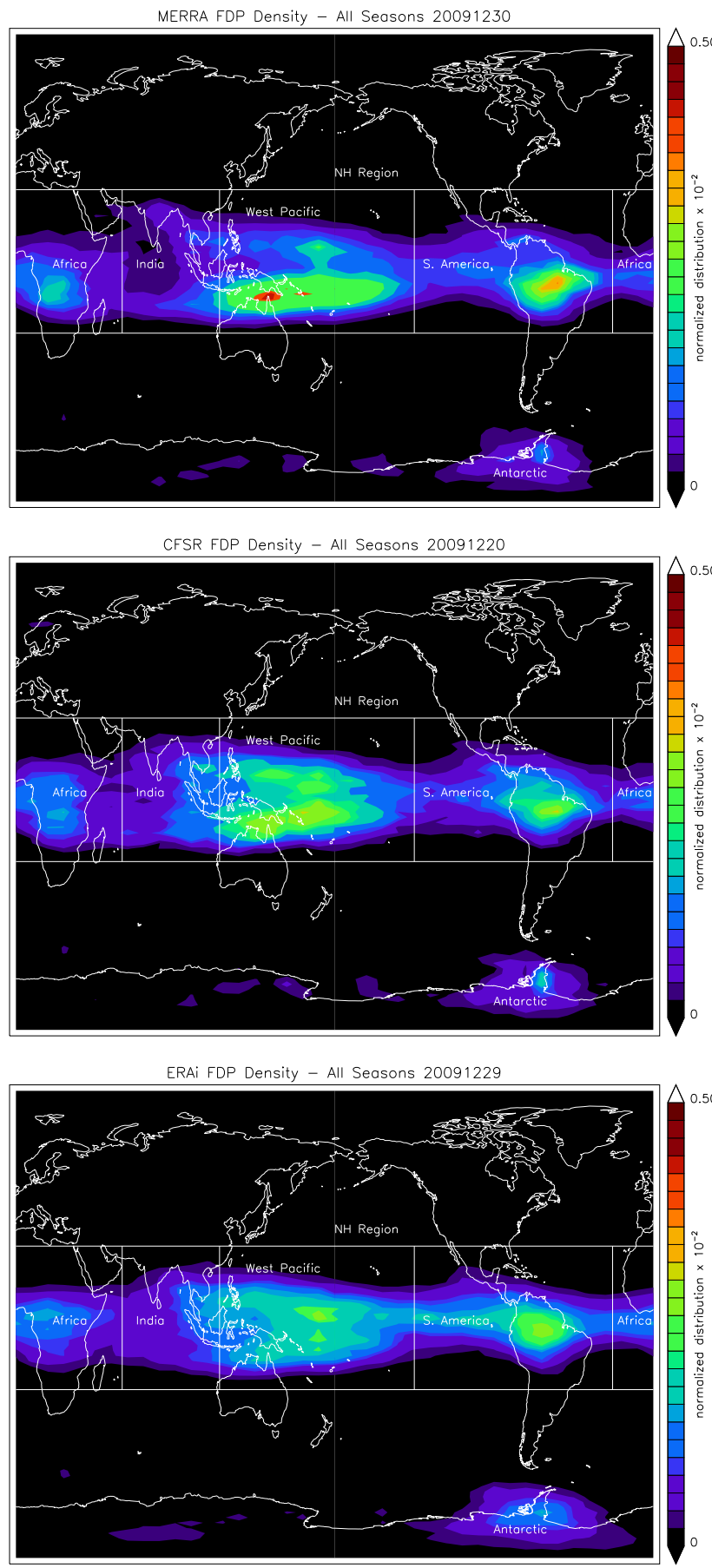

Fig. 3. Density of final dehydration locations from the three reanalyses, (a) MERRA, (b) CFSR, and (c) ERAi.

and the MLS data quality document http://mls.jpl.nasa.gov/ data/v3-3_data_quality_document.pdf). Global average water vapor between 18 and $28 \mathrm{~km}$ is $4.54,4.89,4.13$, and $4.53 \mathrm{ppmv}$ in the MERRA, CSFR, and ERAi simulations and the MLS data, respectively.

The differences between the simulations are less than $20 \%$; the MERRA simulation shows the best agreement to
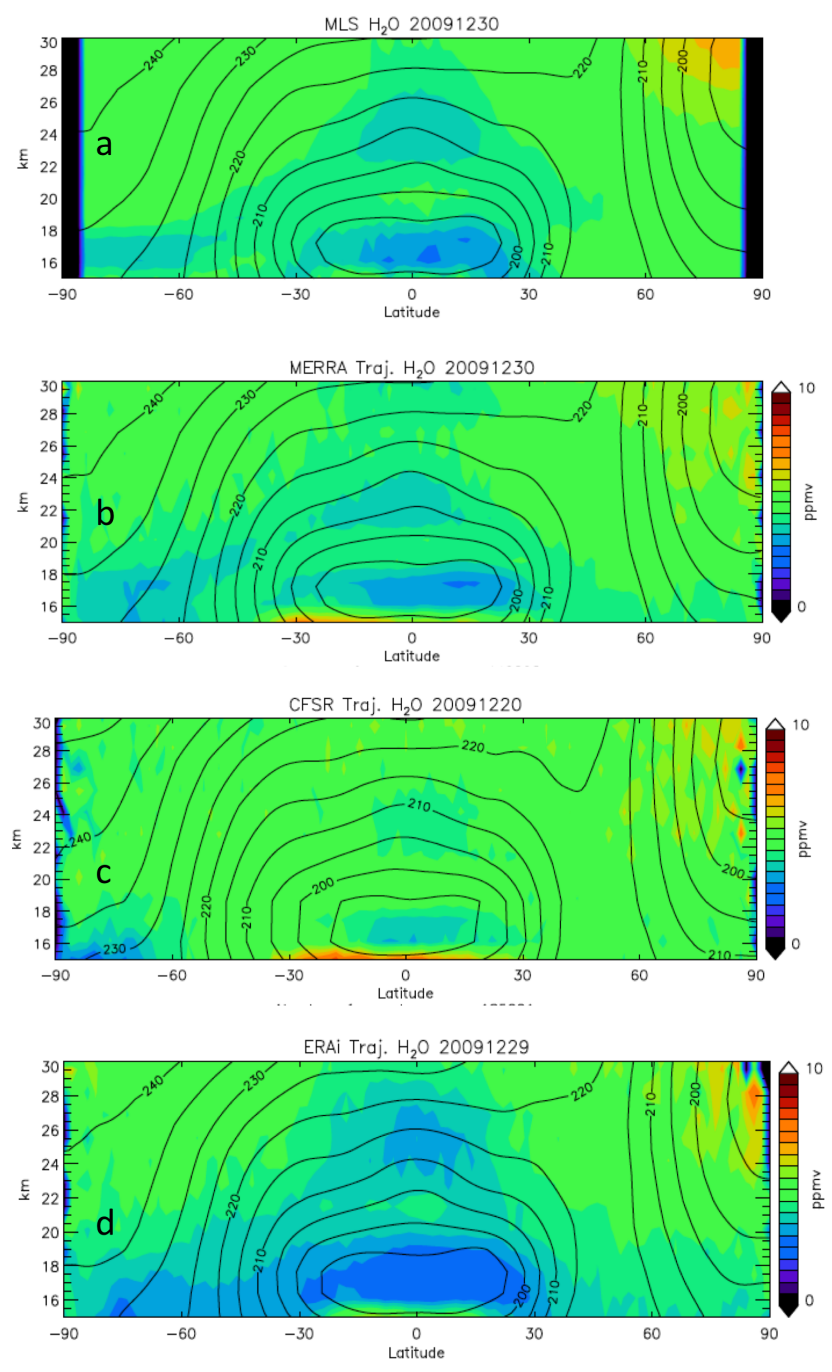

Fig. 4. Water vapor mixing ratio from MLS (a), MERRA (b), CFSR (c), and ERAi (d). Black contours show zonal mean temperature.

MLS, while CFSR is wetter and ERAi is drier. Note that we have adjusted the gravity wave, supersaturation and convection scheme to improve MERRA's agreement with MLS. The gravity wave parameter is the same as that used in SD2011: the convective moistening scheme is applied once a day, and super saturation is set to $104 \%$. Generally, the gravity wave scheme creates colder temperatures and dries the stratosphere whereas increasing the supersaturation threshold or turning on convective moistening increases water vapor. All of these processes independently add or subtract about $<0.5$ ppmv but they are not necessarily additive when used together. The other reanalyses were run with the same free parameter settings as MERRA - this means that it would be possible to tune the parameters to bring the other reanalyses into agreement with MLS.

The tropopause cold region (Fig. 4) is clearly smaller in CFSR and that explains the wetter stratosphere, while ERAi 

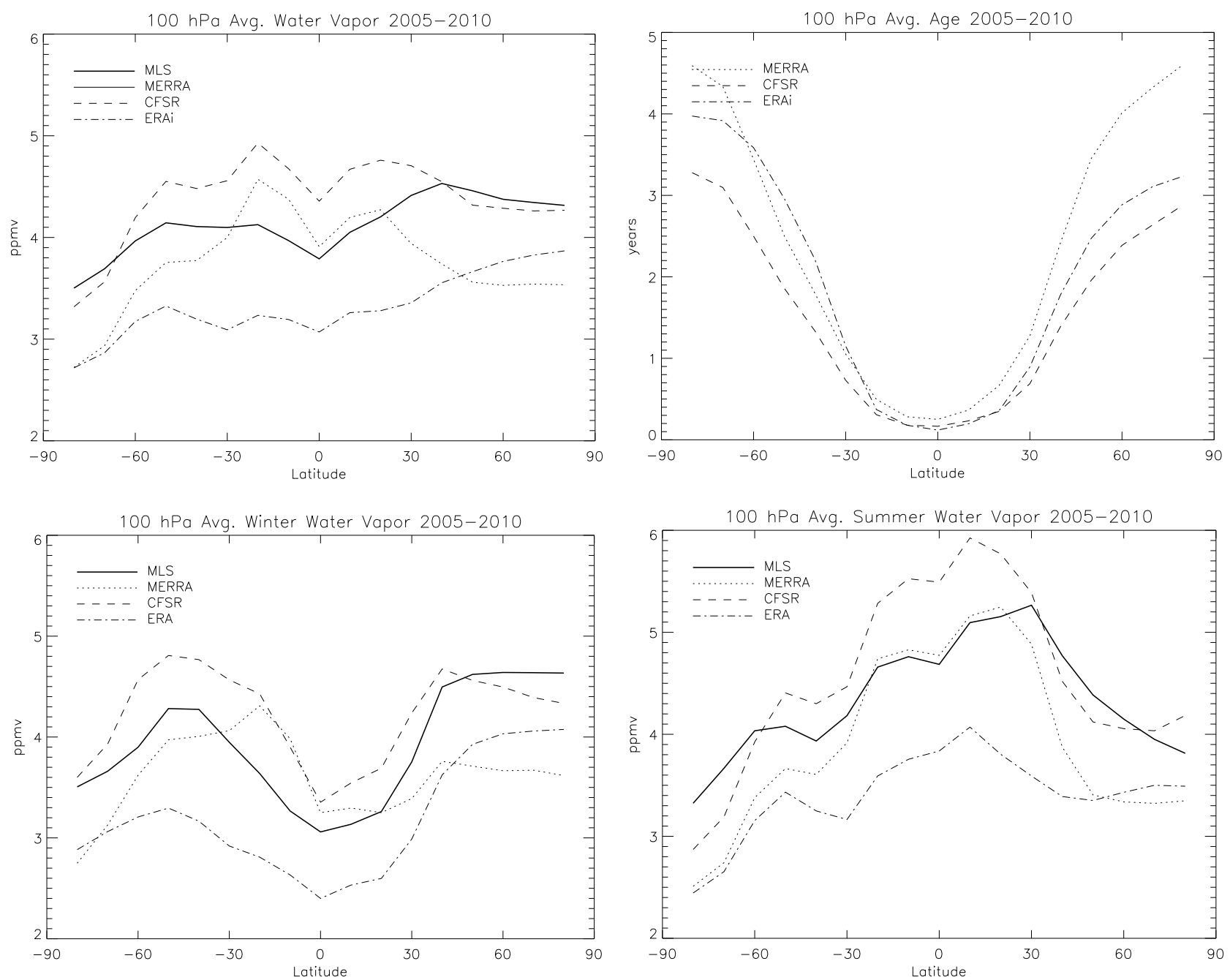

Fig. 5. Zonal (a) water vapor at $100 \mathrm{hPa}$ all seasons (b) mean age. Zonal mean water vapor boreal winter (c) boreal summer (d), MLS, solid, MERRA, dotted, CFSR, dash, ERAi dash-dot.

has a slightly larger cold zone producing a drier stratosphere. The zone of tropical dry air between 22 and $26 \mathrm{~km}$ centered near $25 \mathrm{~km}$ in MLS data is the previous winter tape recorder signal. In MERRA, the center of this zone is roughly at $22.5 \mathrm{~km}$ while in CFSR it is at $25 \mathrm{~km}$ and in ERAi it is at $\sim 25.5 \mathrm{~km}$. Thus MERRA has a slower tropical upward transport relative to the two other reanalyses while ERAi is slightly faster. We will address this observation more quantitatively when we discuss Fig. 8, below.

Figure 5 shows a comparison between the annual, boreal winter (DJF), and boreal summer (JJA) 100-hPa zonalaverage water vapor concentration in the models and in MLS, along with the mean age. In the Southern Hemisphere, Antarctic dehydration forces water vapor values downward for all the models, and this is also seen in the MLS observations. In the Northern Hemisphere, MLS water vapor generally increases toward the North Pole while MERRA and CFSR shows a decrease. ERAi on the other hand shows an increase from its low tropical values. If we look at the winter case (Fig. 5c) MERRA and MLS agree in the tropics but MERRA shows much less water at boreal latitudes. This difference is also apparent in summer. This result suggests that insufficient methane-derived water might be descending from the mid and upper stratosphere in the models, in other words, with the exception of ERAi, the high latitude descent is too weak. However, we note that the northern high-latitude mean age for MERRA is the oldest suggesting that descent in MERRA is more robust than ERAi and CFSR. Clearly, dynamics does not provide the whole explanation of the high latitude water vapor deficit.

Figure 6 shows a comparison between the models run with and without water production from methane oxidation. To make the comparisons cleaner, these runs have a saturation threshold of $100 \%$ and the gravity wave and convection schemes have been turned off. Because more methane is oxidized the longer the parcel spends in the stratosphere, 
2004-2009
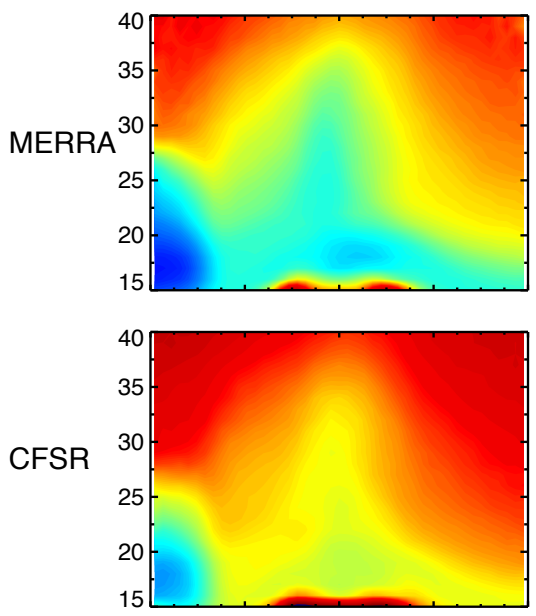

ERA

ERAi

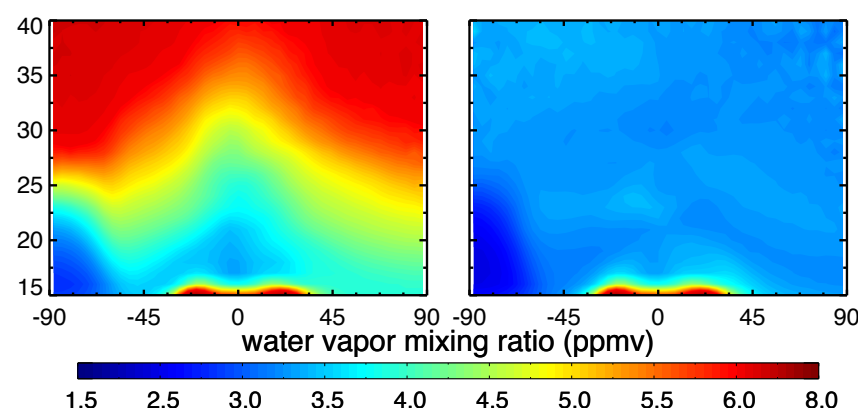

$\mathrm{H}_{2} \mathrm{O}$ w/o $\mathrm{CH}_{4}$
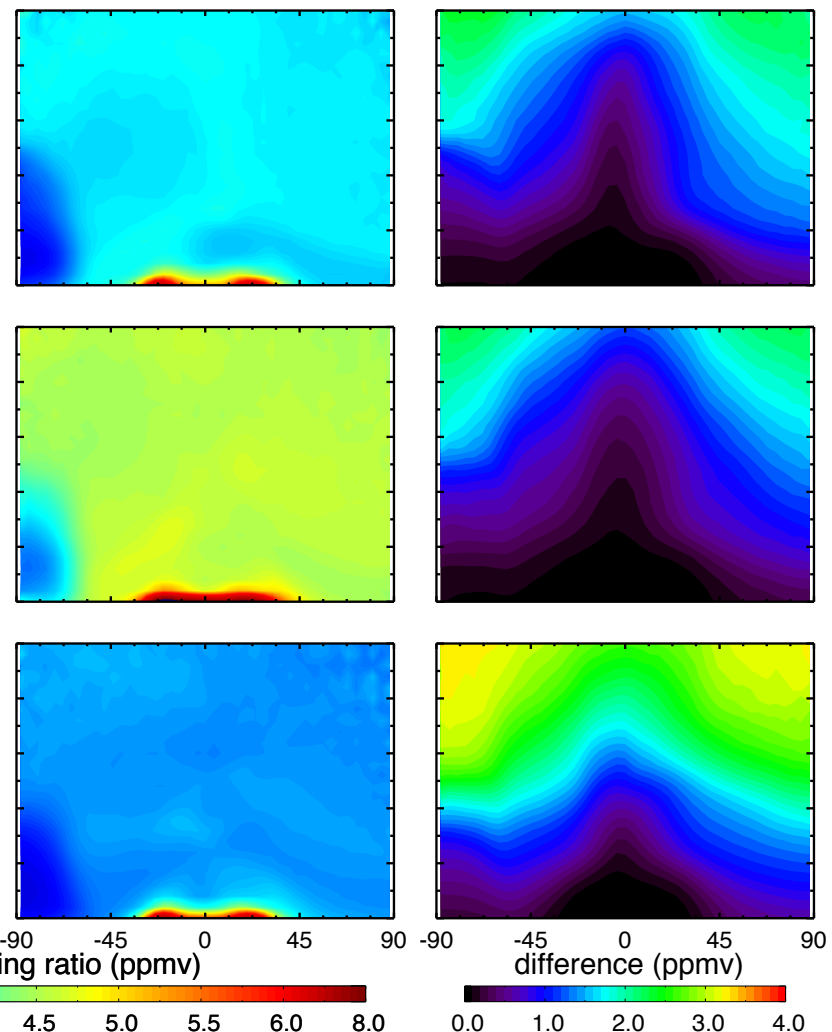

Fig. 6. Comparison of time mean (2004-2009) water vapor. Left column, full simulation including methane oxidation; middle column, without methane oxidation; right column shows difference. These integrations do not include gravity wave parameterization, convective adjustment, and saturation is set to $100 \%$.

water enhancement due to methane shown in Fig. 4 follows the age contours shown in Fig. 2. Without $\mathrm{CH}_{4}$ (center column of Fig. 6), water vapor concentration is more featureless since there are no stratospheric sources or sinks for water, except dehydration in the Antarctic polar vortex. The difference plots between $\mathrm{H}_{2} \mathrm{O}$ with $\mathrm{CH}_{4}$ oxidation and $\mathrm{H}_{2} \mathrm{O}$ without $\mathrm{CH}_{4}$ oxidation are shown in the third column of Fig. 6 and clearly delineate $\mathrm{CH}_{4}$ 's critical role in providing water at higher latitudes and also helps explains the differences between the models away from the tropics. For example, methane is providing much less water at high latitudes in CFSR than in either MERRA or ERAi. This is because CFSR's tropical stratosphere is too ventilated so $\mathrm{CH}_{4}$ moves to higher latitudes and descends out of the model before it can be oxidized. This is consistent with CFSR's young extratropical age-of-air (Fig. 2). On the other hand, $\mathrm{CH}_{4}$-supplied water is significantly enhancing high latitudes in the ERAi case. This result suggests that the ERAi overturning circulation is more rapid than MERRA or CFSR - and this suggestion is quantified in the next section.
The central column also shows the transport of dry air out of the tropics in the $15-20 \mathrm{~km}$ region toward high latitudes as is most clearly seen in the MERRA simulation toward northern high latitudes. This transport also takes place toward southern high latitudes but is less evident due to the massive dehydration. The tropical to extratropical transport of dry air will be discussed further below.

\subsection{Long-term integrations}

In this section we describe the results of long-term integration of the model from 1979-2010 and compare the results with observations.

\subsubsection{Tape recorder simulation}

Figure 7 compares the tape recorder signal in the simulations to observations from a combined HALOE and MLS time series. The plot shows that model does a good job reproducing the tape recorder up to about $30 \mathrm{~km}$ where the lack of parcels creates a noisy signal. Note that the descending QBO's secondary circulation creates "kinks" in the tape signal around 


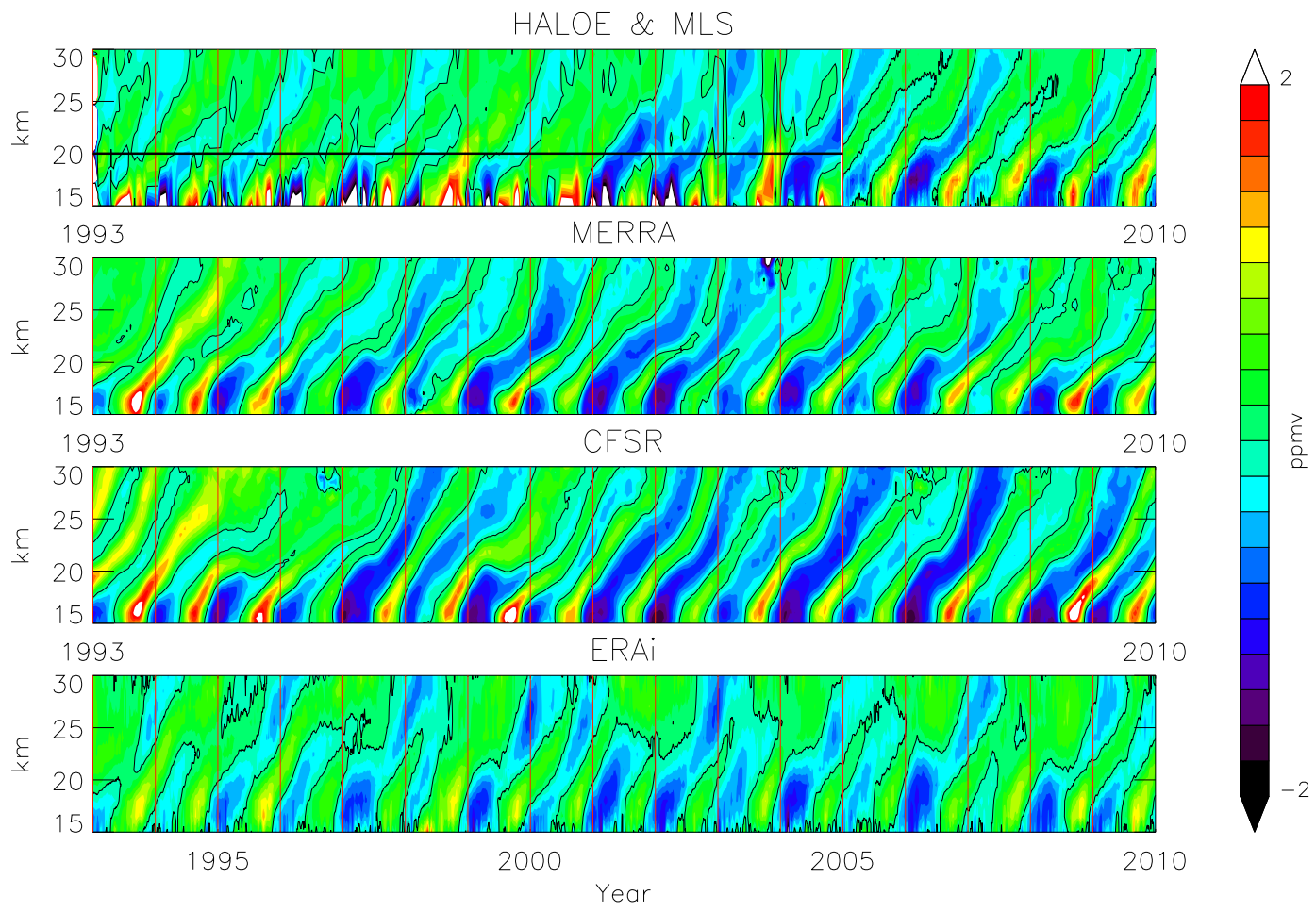

Fig. 7. Water vapor anomalies at the equator from 1993 to 2010. Top, HALOE and MLS combined (HALOE before 2005 - dark line). Top-middle MERRA, bottom middle CFSR, bottom, ERAi.

$24 \mathrm{~km}$ that is also reproduced in the models (Plumb and Bell, 1982; Punge et al., 2009; SD2011).

To better compare the observations with the models, we have computed the correlation between the observations and the model as a function of the lag between the models and measurements. This shifting allows us to quantify the phase lag/lead between the model tape recorder and observations. The results are shown in Fig. 8. The MERRA tape recorder tends to lag the observations as altitude increases, producing an $\sim 2$ month lag at higher altitudes. ERAi tends to lead the observations by about 3 months at higher altitude. The average vertical velocity in the lower tropical stratosphere region is between 0.02 and $0.03 \mathrm{~cm} \mathrm{~s}^{-1}$ (Schoeberl et al., 2008), and thus this result suggests that MERRA tropical upwelling circulation is about $15 \%$ too weak while ERAi is about $30 \%$ too strong, in agreement with Ploeger et al. (2012).

\subsubsection{Upper troposphere/lower stratosphere (UTLS)}

In this section, we analyze the lower stratospheric/upper tropospheric results and compare them to MLS observations. Figure 9 shows the time series of observations and model results at $100 \mathrm{hPa}$. The largest component of water vapor variability is the annual cycle. As part of the annual cycle, winter dry zones propagate to the extra-tropics, arriving at the poles about six months later (Randel et al., 2004) and this is sometimes called the "horizontal tape recorder". The simulations and the observations show that the dry air is held in the tropical region during winter and begins to move poleward in the spring. During late Northern Hemisphere summer, tropical air is significantly moister and that moistening process is likely connected with the Asian monsoon.

Between the models, the water vapor biases compared to MLS are quite evident. Consistent with Fig. 5, the MERRA extra tropics are too dry while CFSR is too wet. As indicated above, the extra tropical dry bias in MERRA driven results appears to be caused by insufficient water descending from higher altitudes where it was produced by methane oxidation as shown in Fig. 6.

The annual cycle in 100-hPa model water vapor (Fig. 9) is complicated by the differences in the zonal means. By adjusting the model zonal means to the MLS zonal mean at each latitude, we can produce a clearer picture of the annual cycle in water vapor. The results are shown in Fig. 10. Now it is quite clear that CFSR's annual tropical cycle is too large compared to observations while MERRA and ERAi's annual cycle is about right. On the other hand, MERRA and ERAi tend to isolate the tropics from the extra-tropics too much with the dry high latitude summer period arriving later than observed.

To quantify the annual cycle amplitude differences further we have performed a regression analysis on the observed and model water vapor fields. In this approach, the data are fit to the annual, biannual, and quarterly cycles, the QBO, solar 

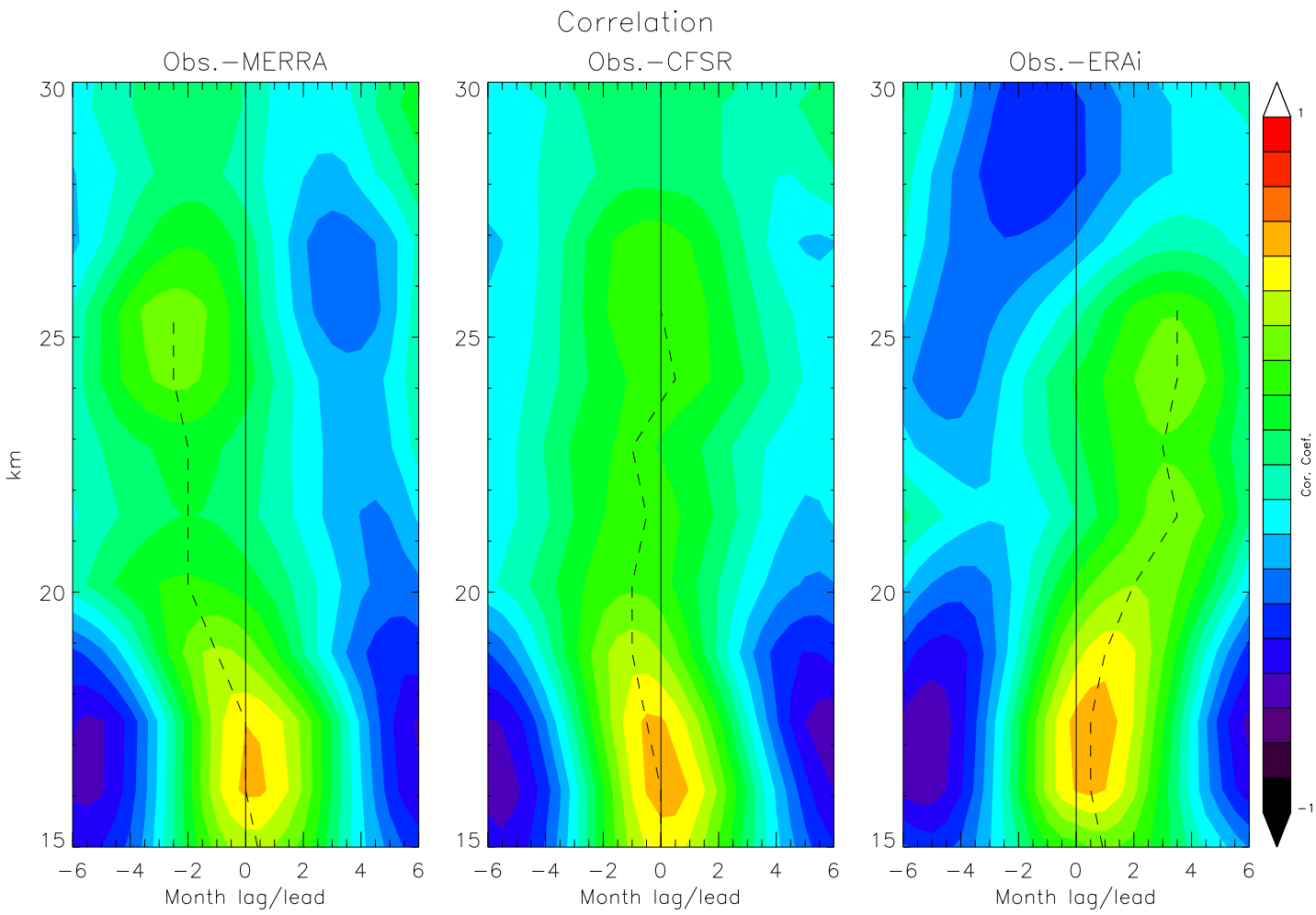

Fig. 8. Correlation of MERRA, CFSR and ERAi results with observations after phase shifting the observations by number of months as indicated. Dashed line shows the peak correlation.

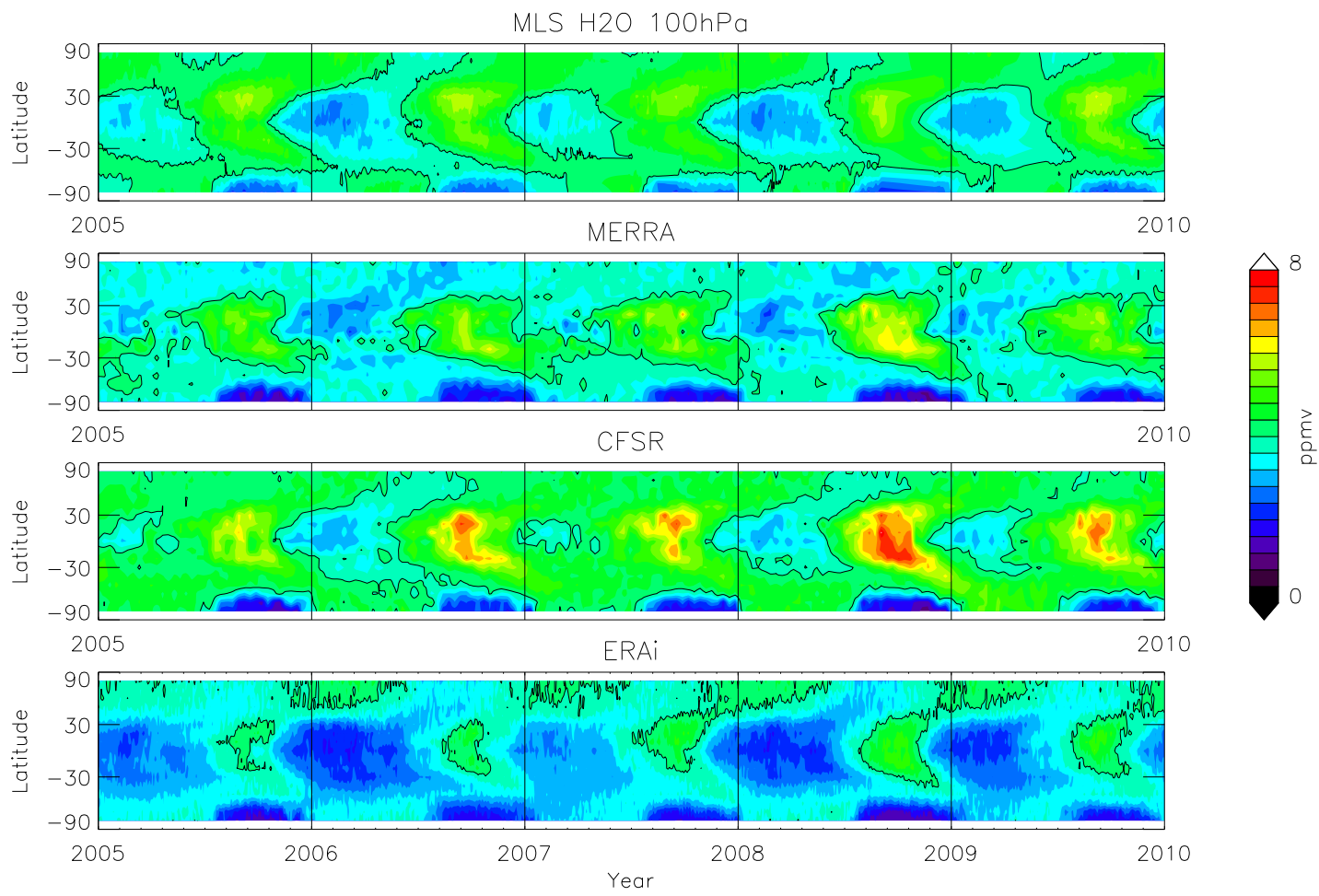

Fig. 9. Times series of $100 \mathrm{hPa}$ water vapor for the three reanalyses compared to MLS as in Fig. 4. 


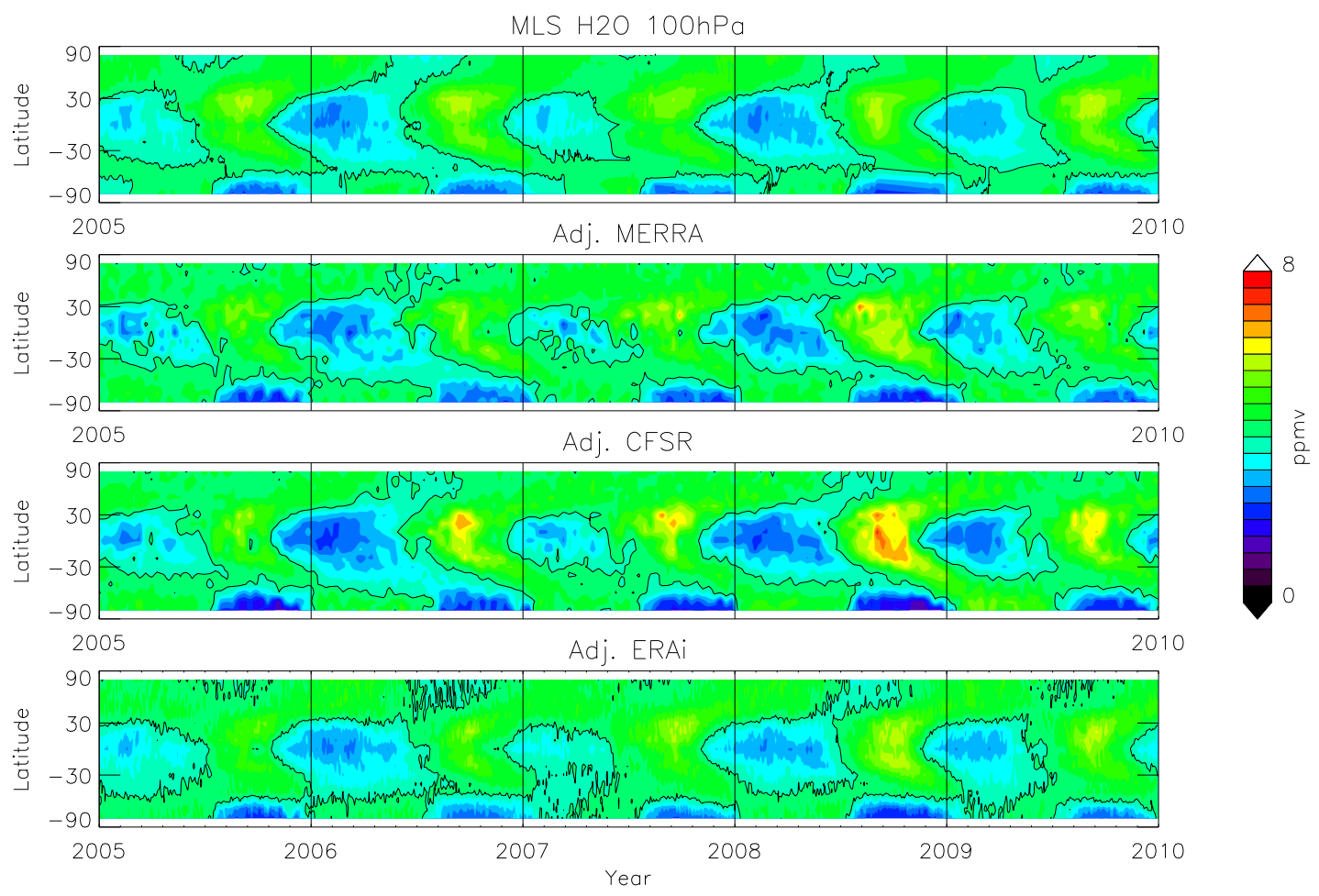

Fig. 10. Same as Fig. 9 but the water vapor fields are adjusted to the MLS zonal mean.

Table 1. Average and Annual Cycle Components for Water Vapor.

\begin{tabular}{lcccc}
\hline Data Set & \multicolumn{2}{c}{ Equator $(100 \mathrm{hPa})$} & \multicolumn{2}{c}{$40^{\circ} \mathrm{N}(100 \mathrm{hPa})$} \\
\hline & Average & Annual Cycle & Average & Annual Cycle \\
\hline HALOE \& MLS & 3.81 & 1.03 & 4.53 & 0.42 \\
Boulder & N/A & N/A & 4.17 & $0.64^{2}$ \\
MERRA & 3.75 & 1.25 & 3.54 & 0.34 \\
CFSR & 4.42 & 1.49 & 4.47 & 0.63 \\
ERAi & 3.08 & 0.95 & 3.46 & 0.27 \\
\hline
\end{tabular}

${ }^{1}$ HALOE values increased by mean difference between HALOE and MLS; HALOE 1993-2005, MLS 2001-2010 ( $\sim 0.6$ ppmv). ${ }^{2}$ Boulder balloon data over same period have been convolved with the MLS retrieval kernels. Satellite and model values are zonal means while balloon data is only over Boulder.

cycle, ENSO, and volcanic eruptions (Stolarski et al., 2006). As a consistency check on the trends, we also have performed a simple linear fit to the data and found that the overall trends agree. The annual cycle component is listed in Table 1.

As noted above the annual cycle is relatively larger in CFSR compared to MERRA and ERAi both in the tropics and extra tropics. Compared to observations, the extratropical annual cycles are too weak in MERRA and ERAi, but too strong for CFSR.

We have also used the regression model to examine longterm trends in the observations and model results after the annual, ENSO, volcanic, QBO, etc. perturbations are removed. Table 2 summarizes our estimates of the net change in water vapor over two periods, 1982-2010 (comparison against the Boulder data) and 1993-2010 (comparison against the combined HALOE+MLS data). The net change is computed by multiplying the linear trend by the number of years of data. We also show model net changes for the same period. The long-term trends for HALOE+MLS and Boulder data sets are not consistent over the 1993-2010 period. This inconsistency may be a result of the interference from the Pinatubo aerosol in HALOE retrievals at the beginning of the analysis period. HALOE water, for example, shows a clear decrease at $40^{\circ} \mathrm{N}$ from 1993-1995, which is at odds with the Boulder data (Hurst et al., 2011). We also note that the models report 
Table 2. Net change in water vapor from models and observations in ppmv over indicated period

\begin{tabular}{lrrrr}
\hline \multicolumn{5}{c}{ From 1993-2010- HALOE+MLS } \\
\hline Latitude/Pressure & MERRA & CFSR & ERAi & Observations \\
\hline $0^{\circ} \mathrm{N} / 100 \mathrm{hPa}$ & $0.14 \pm 0.05$ & $0.05 \pm 0.06$ & $0.16 \pm 0.02$ & $-0.57 \pm 0.06$ \\
$0^{\circ} \mathrm{N} / 30 \mathrm{hPa}$ & $-0.18 \pm 0.03$ & $-0.55 \pm 0.05$ & $0.12 \pm 0.02$ & $-0.23 \pm 0.02$ \\
$40^{\circ} \mathrm{N} / 100 \mathrm{hPa}$ & $0.12 \pm 0.02$ & $-0.2 \pm 0.03$ & $0.13 \pm 0.01$ & $-0.36 \pm 0.04$ \\
$40^{\circ} \mathrm{N} / 30 \mathrm{hPa}$ & $-0.4 \pm 0.017$ & $-0.6 \pm 0.03$ & $0.11 \pm 0.01$ & $-0.45 \pm 0.03$ \\
\hline \multicolumn{5}{c}{ From 1982-2010- Boulder } \\
\hline $40^{\circ} \mathrm{N} / 100 \mathrm{hPa}$ & $-0.2 \pm 0.02$ & $-0.65 \pm 0.03$ & $0.42 \pm 0.01$ & $-0.12 \pm 0.2$ \\
$40^{\circ} \mathrm{N} / 30 \mathrm{hPa}$ & $-0.13 \pm 0.01$ & $-0.67 \pm 0.02$ & $0.45 \pm 0.01$ & $0.46 \pm 0.18$ \\
\hline
\end{tabular}

HALOE+MLS data analyzed within $\pm 5^{\circ}$ window of target latitude. The error bars are 1 sigma uncertainty.

different trend magnitudes and even different signs for both periods.

\section{Summary and conclusions}

This paper extends the results of stratospheric water vapor simulations from the forward trajectory model described in SD2011. In SD2011, we used the MERRA reanalyses; in this paper, we extend analysis period back to 1979 and include the NOAA CFSR and ECMWF ERAi reanalyses as well.

CFSR and ERAi dehydration patterns show less dehydration occurring in the TWP Southern Hemisphere than MERRA. All three models show dehydration taking place over South America as well as East Asia. The CFSR tropical tropopause temperatures are somewhat warmer than MERRA leading to $~ 3 / 4 \mathrm{ppmv}$ more water vapor at $100 \mathrm{hPa}$ in the former. ERAi, on the other hand, is cold biased relative to the other reanalyses, producing $3 / 4$ ppmv lower water vapor at $100 \mathrm{hPa}$ than MERRA. Water vapor from methane oxidation is critical in explaining the increase in water vapor with latitude toward the North Pole. In the Southern Hemisphere, Antarctic dehydration causes a decrease in water with latitude toward the South Pole. Extra tropical water vapor is controlled by the stratospheric overturning circulation and changes in that circulation may be evident in future measurements of stratospheric water.

The models do a reasonable job of reproducing the tropical tape recorder and mid-latitude water vapor observations. We find that the ERAi water vapor signal is moving upward too fast in the $17-22 \mathrm{~km}$ region, suggesting about $30 \%$ too high a vertical velocity in that region. CFSR water vapor signals move upward at about the right speed, and MERRA vertical velocities are too low by about $15 \%$.

Over Boulder, the simulated annual cycles in water vapor are weaker than in the balloon data set, but consistent with HALOE+MLS time series. The models and the combined HALOE+MLS observations show no significant longterm trends in the tropical $100-\mathrm{hPa}$ water vapor concentration; however, outside of the tropical lower stratosphere, the models do not agree on the magnitude of the trends nor its sign. One possible explanation is that there is too little high quality observational data to constrain the model TTL biases in the early periods of the long-term integrations.

Acknowledgements. A. Dessler acknowledges NASA Aura grant NNX08AR27G to Texas A\&M University. We thank K. Bowman for help on the trajectory code and S. Pawson for information on the MERRA data set. We thank Karen Rosenlof for providing the MLS-sampled Boulder balloon data. We also thank Bernard Legras for his help with the ERAi reanalysis and Bill Randel for additional comments.

Edited by: M. Dameris

\section{References}

Alcala, C. M. and Dessler, A. E.: Observations of deep convection in the tropics using the TRMM precipitation radar, J. Geophys. Res., 107, 4792, doi:10.1029/2002JD002457, 2002.

Bosilovich, M. G., Chen, J., Robertson, F. R., and Adler, R. F.: Evaluation of global precipitation in reanalyses, J. Appl. Meteor. Climatol., 47, 2279-2299, doi:10.1175/2008JAMC1921.1, 2008.

Chiou, E. W., McCormick, M. P., McMaster, L. R., Chu, W. P., Larsen, J. C., Rind, D., and Oltmans, S.: Intercomparison Of Stratospheric Water Vapor Observed By Satellite Experiments: Stratospheric Aerosol And Gas Experiment II Versus Limb Infrared Monitor Of The Stratosphere And Atmospheric Trace Molecule Spectroscopy, J. Geophys. Res., 98, 4875-4887, 1993.

Corti, T., Luo, B. P., deReus, M., Brunner, D., Cairo, F., Mahoney, M. J., Matucci, G., Matthey, R., Mitev, V., dos Santos, F. H., Schiller, C., Shur, G., Sitnikov, N. M., Spelten, N., Vossing, H. J., Borrmann, S., and Peter, T.: Unprecedented evidence for overshooting convection hydrating the tropical stratosphere, Geophys. Res. Lett., 35, L10810, doi:10.1029/2008GL033641, 2008.

Danielsen, E. F.: Trajectories - isobaric, isentropic and actual, J. Meteorol., 18, 479-486, 1961.

Dee, D. P., Uppala, S. M., Simmons, A. J., et al.: The ERAInterim reanalysis: configuration and performance of the data assimilation system, Q. J. Roy. Meteor. Soc., 137, 553-597, doi:10.1002/qj.828, 2011. 
Dessler, A. E., Hanisco, T. F., and Fueglistaler, S. A.: Effects of convective ice lofting on $\mathrm{H}_{2} \mathrm{O}$ and $\mathrm{HDO}$ in the tropical tropopause layer, J. Geophys. Res., 112, D18309, doi:10.1029/2007JD008609, 2007.

Evans S., Toumi, R., Harries, J., Chipperfield, M., and Russell, J.: Trends in stratospheric humidity and the sensitivity of ozone to these trends, J. Geophys. Res., 103, 8715-8725, 1998.

Forster, P. M. D. and Shine, K. P.: Stratospheric water vapour changes as a possible contributor to observed stratospheric cooling, Geophys. Res. Lett., 26, 3309-3312, 1999.

Fueglistaler, S., Bonazzola, M., Haynes, P. H., and Peter, T.: Stratospheric water vapor predicted from the Lagrangian temperature history of air entering the stratosphere in the tropics, J. Geophys. Res., 110, D08107, doi:10.1029/2004JD005516, 2005.

Fueglistaler, S., Dessler, A. E., Dunkerton, T. J., Folkins, I., Fu, Q., and Mote, P. W.: The tropical tropopause layer, Rev. Geophys., 47, doi:10.1029/2008RG000267, 2009.

Hurst, D. F., Oltmans, S. J., Vomel, H., Rosenlof, K. H., Davis, S. M., Ray, E. A., Hall, E. G., and Jordan, A.: Stratospheric water vapor trends over Boulder, Colorado: Analysis of the 30 year Boulder record, J. Geophys. Res., 116, D02306, doi:10.1029/2010JD015065, 2011.

Jensen, E. J. and Pfister, L.: Transport and freeze-drying in the tropical tropopause layer, J. Geophys. Res., 109, D02207, doi:10.1029/2003JD004022, 2004

Jensen, E. J., Smith, J. B., Pfister, L., Pittman, J. V., Weinstock, E. M., Sayres, D. S., Herman, R. L., Troy, R. F., Rosenlof, K., Thompson, T. L., Fridlind, A. M., Hudson, P. K., Cziczo, D. J., Heymsfield, A. J., Schmitt, C., and Wilson, J. C.: Ice supersaturations exceeding $100 \%$ at the cold tropical tropopause: implications for cirrus formation and dehydration, Atmos. Chem. Phys., 5, 851-862, doi:10.5194/acp-5-851-2005, 2005.

Johnson, D. G., Jucks, K. W., Traub, W. A., and Chance, K. V.: Isotopic composition of stratospheric water vapor: Implications for transport, J. Geophys. Res., 106, 12219-12226, 2001.

Liu, Y. S., Fueglistaler, S., and Haynes, P.: Advection-condensation paradigm for stratospheric water vapor, J. Geophysical Res., 115, D24307, doi:10.1029/2010JD014352, 2010.

Kramer, M., Schiller, C., Afchine, A., Bauer, R., Gensch, I., Mangold, A., Schlicht, S., Spelten, N., Sitnikov, N., Borrmann, S., de Reus, M., and Spichtinger, P., Ice supersaturations and cirrus cloud crystal numbers, Atmos. Chem. Phys., 9, 3505-3522, doi:10.5194/acp-9-3505-2009 2009.

Mote, P. W., Rosenlof, K. H., McIntyre, M. E., Carr, E. S., Gille, J. C., Holton, J. R., Kinnersley, J. S., Pumphrey, H. C., Russell III, J. M., and Waters, J. W.: An atmospheric tape recorder: The imprint of tropical tropopause temperatures on stratospheric water vapor, J. Geophys. Res., 101, 3989-4006, 1996.

Murphy, D. M. and Koop, T.: Review of the vapour pressures of ice and supercooled water for atmospheric applications, Q. J. Roy. Meteor. Soc., 131, 1539-1565, 2005.

Ploeger, F., Konopka, P., Gunther, G., J.-U. Grooß, and Muller, R.: Impact of the vertical velocity scheme on modeling transport across the tropical tropopause layer, J. Geophys. Res., 115, D03301, doi:10.1029/2009JD012023, 2010.

Ploeger, F., Fueglistaler, S., Grooß, J.-U., Gunther, G, Konopka, P., Liu, Y. S., Muller, R., Ravegnani, F., Schiller, C., Ulanovski, A., and Riese, M.: Insight from ozone and water vapour on transport in the tropical tropopause layer (TTL), Atmos. Chem. Phys.,
407-419, doi:10.5194/acp-11-407-2011, 2011.

Ploeger, F., Konopka, P., Müller, R., Fueglistaler, S., Schmidt, T., Manners, J. C., Grooß, J.-U., Günther, G., Forster, P. M., and Riese, M.: Horizontal transport affecting trace gas seasonality in the Tropical Tropopause Layer (TTL), J. Geophys. Res., 117, D09303, doi:10.1029/2011JD017267, 2012.

Plumb, R. A.: Stratospheric Transport, J. Meteor. Soc. Jpn., 80, 793-809, 2002.

Plumb, R. A. and Bell, R. C.: A model of the quasi-biennial oscillation on an equatorial beta-plane, Q. J. Roy. Meteor. Soc., 108, 335-352, 1982.

Prather, M. J., Zhu, Z., Strahan, S. E., Steenrod, S. D., and Rodriguez, J. M.: Quantifying errors in trace species transport modeling, PNAS, 105, 19617-19621, 2008.

Randel, W. J., Wu, F., Oltmans, S. J., Rosenlof, K., and Nedoluha, G. E.: Interannual Changes of Stratospheric Water Vapor and Correlations with Tropical Tropopause Temperatures, J. Atmos. Sci., 61, 2133-2148, 2004.

Read, W. G., Lambert, A., Bacmeister, J., et al.: Aura Microwave Limb Sounder upper tropospheric and lower stratospheric $\mathrm{H} 2 \mathrm{O}$ and relative humidity with respect to ice validation, J. Geophys. Res. 112, D24S35, doi:10.1029/2007JD008752, 2007.

Rienecker, M., Suarez, M. J., Gelaro, R., et al.: MERRA: NASA's Modern-Era Retrospective Analysis for Research and Applications, J. Climate, 24, 3624-3648, doi:10.1175/JCLI-D-1100015.1, 2011.

Rosenlof, K. H. and Reid, G. C.: Trends in the temperature and water vapor content of the tropical lower stratosphere: Sea surface connection, J. Geophys. Res., 113, D06107, doi:10.1029/2007JD009109, 2008.

Saha, S. et al.: The NCEP Climate Forecast System Reanalysis, B. Am. Meteor. Soc., 91, 1015-1057, 2010.

Schiller, C., Grooß, J.-U., Konopka, P., Plöger, F., Silva dos Santos, F. H., and Spelten, N.: Hydration and dehydration at the tropical tropopause, Atmos. Chem. Phys., 9, 9647-9660, doi:10.5194/acp-9-9647-2009, 2009.

Schoeberl, M., Douglass, A., Zhu, Z., and Pawson, S.: A comparison of the lower stratospheric age spectra derived from a general circulation model and two data assimilation systems, J. Geophys. Res., 108, 4113, doi:10.1029/2002JD002652, 2003.

Schoeberl, M. R., Douglass, A. R., Stolarski, R. S., Pawson, S., Strahan, S. E., and Read, W.: Comparison of lower stratospheric tropical mean vertical velocities, J. Geophys. Res., 113, D24109, doi:10.1029/2008JD010221, 2008.

Schoeberl, M. R. and Dessler, A. E.: Dehydration of the stratosphere, Atmos. Chem. Phys., 11, 8433-8446, doi:10.5194/acp11-8433-2011, 2011.

Solomon, S., Rosenlof, K. H., Portmann, R. W., Daniel, J. S., Davis, S. M., Sanford, T. J., and Plattner, G.-K.: Contributions of stratospheric water vapor to decadal changes in the rate of global warming, Science, 327, 1219-1223, doi:10.1126/science.1182488, 2010.

Stolarski, R. S., Douglass, A. R., Steenrod, S., and Pawson, S.: Trends in stratospheric ozone: Lessons learned from a 3D chemical transport model, J. Atmos. Sci., 63, 1028-1041, 2006.

Tzella, A. and Legras, B.: A Lagrangian view of convective sources for transport of air across the Tropical Tropopause Layer: distribution, times and the radiative influence of clouds, Atmos. Chem. Phys., 11, 12517-12534, doi:10.5194/acp-11-12517-2011, 2011. 
Vogel, B., Feck, T., and Grooß, J.-U.: Impact of stratospheric water vapor en- hancements caused by $\mathrm{CH}_{4}$ and $\mathrm{H}_{2} \mathrm{O}$ increase on polar ozone loss, J. Geophys. Res., 116, D05301, doi:10.1029/2010JD014234, 2011.

Wohltmann, I. and Rex, M.: Improvement of vertical and residual velocities in pressure or hybrid sigma-pressure coordinates in analysis data in the stratosphere, Atmos. Chem. Phys., 8, 265272, doi:10.5194/acp-8-265-2008, 2008.
Wright, J. S., Fu, R., Fueglistaler, S., Liu, Y. S., and Zhang, Y.: The influence of summertime convection over Southeast Asia on water vapor in the tropical stratosphere, J. Geophys. Res., 116, D12302, doi:10.1029/2010JD015416, 2011.

Zipser, E. J., Cecil, D. J., Liu, C., Nesbitt, S. W., and Yorty, D. P.: Where are the most intense thunderstorms on Earth?, B. Am. Meteor. Soc., 87, 1057-1071, 2006. 